\title{
Evaluating M-Learning System Adoption by Faculty Members in Saudi Arabia Using Concern Based Adoption Model (CBAM) Stages of Concern
}

\author{
https://doi.org/10.3991/ijet.v14i05.8296 \\ Mohammed Al Masarweh \\ King Abdulaziz University, Jeddah, Saudi Arabia \\ malmasarweh@kau.edu.sa
}

\begin{abstract}
This study assesses the use of an m-learning system by faculty members in Saudi Arabia using a new approach and methodology that have been used in Gulf region. Optimum use of educational technology requires consideration of requirements, obstacles and opportunities expected from user interaction with such systems and tools. While the use of m-learning in Saudi Arabia is relatively new, different research studies have investigated the use of m-learning in Saudi Arabia using different models. Most of the presented models investigated the acceptance and use from student perspectives, with little consideration of adoption by faculty members, their use of m-learning systems and their concerns (i.e. facilitators and barriers) as users. Some of the used models managed to provide significant results in relation to m-learning use, while others were found to lack a systematic and appropriate methodology. Concern Based Adoption Model (CBAM), which has widely used in the United State of America (USA), Canada and (more recently) the Middle East (particularly Jordan), was used in this study to investigate m-learning adoption as an educational technology in Saudi Arabia. This framework provides tools to evaluate the use of educational technology within educational settings. This framework has not previously been used in Saudi Arabian educational research literature, and it is believed that the output will be valuable for enhancing the level of concern, adoption and use of m-learning in the future.
\end{abstract}

Keywords-Assessing, CBAM, Models, M-learning, Saudi Universities, Stages of Concern, information systems.

\section{$1 \quad$ Introduction}

The ongoing proliferation of mobile learning (m-learning) is becoming a trend and concern for different educational institutions and stakeholders seeking to use different approaches towards learning, reflecting changes in learner characteristics and consumer-driven trends arising from the ubiquity of smartphone technology and use; it should be noted from the outset that laptops are also considered to be part of $\mathrm{m}$ learning due to their functional mobility features [1], but the focus and concern in this study is Smartphone devices using the internet as a medium via $3 \mathrm{G}$ or $4 \mathrm{G}$ networks. 
The use of m-learning within higher educational contexts in Saudi Arabia has been researched and investigated by different research studies in relation to technology, interaction, students, faculty members, culture and content [2,4]. Most studies demonstrated positive impacts of m-learning in the educational process and potential for great improvements in quality and adoption, especially with the total saturation of mobile phone subscriptions in Saudi Arabia (having exceeded 100\% for many years) and increasingly ubiquitous use of mobile internet [4]. However, research studies have not ignored the substantive challenges and concerns of using and implementing $\mathrm{m}$-learning with respect to different technological, pedagogical, social, environmental and educational factors. The success of m-learning as an educational technology solution depends on numerous factors, and ultimately on the effectual participation and engagement of users with the services and resources provided by the technology $[1,4]$. Consequently it is essential to monitor and evaluate the extent to which mlearning adoption is successful, which enables m-learning systems to be improved in terms of user-related issues (e.g. perceived ease of use), content (e.g. the quality of education), technical and pedagogical services, policies and practices. Different tools and methodologies have been used to investigate and evaluate the use of m-learning in Saudi Arabia based on numerous surveys and questionnaires using different indicators [2, 5]. These individual research efforts produced valuable data and insights, but methodologically there is a lack of standardization or large-scale study of m-learning adoption, and indeed most studies are consciously targeted to very specific contexts such as particular educational institutions within certain countries in order to generate empirical data. While researchers in different countries using different customized tools and methodologies for investigation help identify similar factors across studies, which can be used for tentative generalization, this is very limited in terms of its utility to practical implementations. As m-learning (and e-services generally) mature, there is a growing need for standardized tools for investigating $\mathrm{m}$ learning as a benchmark for measuring against future development, with self or other adopters of m-learning, internationally [6]. The aim of this research is to investigate the adoption of m-learning among faculty members in Saudi universities based on a robust and standardized evaluation model. While considering available models, this research justifies the use of the Concern Based Adoption Model (CBAM) as a standard.

\section{Faculty Member Evaluation Models}

The literature provides different models that have been used in different research studies for evaluating changes in the use of technology within classroom contexts or other educational settings by instructors, faculty members, educators and professors. One of the first models was the "The Apple Classrooms of Tomorrow" (TACOT), constructed according to five stages corresponding to instructors' responses and concerns about using computers in classrooms [9]. The five stages in this model were defined as entrance, acceptance, adjustment, appropriation and creation. The stages beginning with the entrance stage of the technology were developed to guide 
instructors to the acceptance stage for using it; subsequently, continual engagement with raised concern during the adjustment phase involved adjusting the use of technology in support of learning and educational pedagogy in response to learner needs in situ (i.e. arising from real use of the system). Next, the stages advance to reach appropriation, wherein instructors reach creation capability, being able to create applications for educational purposes using computers. The same stages can be adopted and used with m-learning as the majority of used devices use operating systems and have computational powers and wide support for creating applications using different development environments. A different model was created in the late 1998 by [10], consisting of four different stages similar to TACOT, with the removal of the entrance stage. The stages ('concerns') were named personal productivity concern, lecture enhancement concern, interactivity concern, and student centered learning concern. Another model developed by [11] produced a sequence of views related to higher education instructors' use of computers. The model included the following stages: tools for teaching, productivity tools, multimedia and technologies tools, and facilitator of communications with instructors and learners. The previously mentioned models have been seen as a method for examining different reactions and measuring the scope or level of engagement among faculty members towards the use of m-learning technology. However, those models were found to be unable to provide a valid tool capable of formally evaluating instructors' concerns, adoption, adaptation and interaction. In the same context, a model presented by [12] named the Technology Learning Cycle (TCL) concentrated on instructors' responses against using technologies in education. The TCL model provides five stages: awareness, exploration and filtration, learning, personal and professional application, sharing and reflection. Different research studies investigated the self-efficacy viewpoint through defining faculty members' responses to technological innovations such as the "Microcomputer Utilization in Teaching Efficacy Belief Instrument", MUTEBI model. Moreover, the Beliefs About Teaching with Technology" (BATT) [13] was based on Ford's motivational systems theory, which provides four different stages: capacity beliefs, personal goals, emotional stimulation and context beliefs). The BATT model is similar to MUTEBI in emphasizing the measurement of instructors' skills and beliefs in relation to technology acceptance and use, with the addition of more significance to approaching the factors affecting technology adoption. It is important to understand that the previously presented models were found valuable when the concerns are related to the self-efficacy attitudes of instructors in the change (i.e. adoption) process. In addition to what has been presented in terms of evaluation models, there are different tools and models constructed without being based on theoretical foundations, mainly used to validate technological use in education through reiterating the use of such tools and models in order to capture change over time (e.g. EnGauge, Flashlight and TAGLIT), which are mainly intended for practitioner use and not for academic investigation [7]. 


\section{The Concerns-Based Adoption Model}

Measuring the change in response to the use of technological innovation within educational settings was the main aim of the previously presented tools and models. Moreover, they were not found comprehensive or suitable to cover wider aspects of investigation $[6,8]$. CBAM came as a response to provide a larger scale methodology to investigate behavioral changes relating to the adoption and use of technological innovations in educational settings. CBAM has been shown to be an effective theoretical model for evaluating change in practice, with a robust framework for contextualizing findings [14]. This research study used CBAM as a framework tool and methodology to evaluate the engagement and use of m-learning by faculty members in Saudi universities. The main aim of CBAM is to provide a framework that provides different tools to predict, measure, describe and explain the change in progression that faculty members experience when using an educational innovation. In addition, the framework should be capable of defining how the change in progression is affected by the attitude of changing facilitators [15]. CBAM as a framework consists of three different tools: the first tool that was developed was Stages-of-Concern (SoC), the aim of which was based on investigating feelings and concerns related to using an innovation [16]. The Level-of-Use (LoU) was the second tool concentrated on investigating skills, knowledge and behavior of faculty members in relation to the use of educational technology [17]. The third tool in the CBAM framework was Innovation Configuration (IC), which was used for defining the variable features of implementation scope of using an educational technology in practice [18]. It is important to understand that using all the tools provided by CBAM framework is optional, and depends on the aim and needs of investigation. However, it is also important to understand that, for gaining complete, related and logical understanding of the effect of educational technology use on developing CBAM, the tools must be used in the presented order. The use of CBAM framework is mainly popular in the USA, Western Europe, Australia, with some recent studies using it in the Middle East, in Jordan [6,8]. This research study benefits from using CBAM as standardized framework for measuring the results against foreign and neighboring countries in the Middle East and thus helps in establishing a benchmark for future enhancements and engagements with educational innovations and technology.

\section{CBAM Stages of Concern}

As mentioned earlier, SoC was the first developed tool for CBAM framework, and it is the first tool that needs to be used for investigating the use of technology within the educational scope of faculty members' involvement and concern. The SoC focuses on the feelings and concerns in response to the use educational technology, and it is ordered into seven stages that evolve gradually from faculty members being unconcerned to using educational technology, being self-focused, focus on tasks and focus on using technology and its impacts on students. The following table shows each stage and its implication [16]: 
Table 1. Stages of concern

\begin{tabular}{|c|}
\hline SELF \\
\hline O Awareness \\
\hline Faculty members at this stage show little concern about their engagement with the technology used. \\
\hline 1 Informational \\
\hline $\begin{array}{l}\text { Faculty members at this stage show more attentiveness for the use of educational technology, and they } \\
\text { develop more interest to discover more details about it. }\end{array}$ \\
\hline 2 Personal \\
\hline $\begin{array}{l}\text { Faculty members in these stages are found to be undecided about the needs of educational technology and } \\
\text { their ability to address those demands and define their role in relation to its use. The users found in this } \\
\text { stage are generally analyzing and characterizing the relationship between using the educational technology } \\
\text { and the reward structure of the organization, to be able to define their responsibility in decision making and } \\
\text { personal commitment. }\end{array}$ \\
\hline TASK \\
\hline 3 Management \\
\hline $\begin{array}{l}\text { Faculty members in this stage concentrate on methods and tasks related to using educational technology } \\
\text { and the use of different information and engagement with different resources. Moreover, there is clear } \\
\text { reflection on effectiveness, categorizing, administrating and scheduling. }\end{array}$ \\
\hline IMPACT \\
\hline 4 Consequence \\
\hline $\begin{array}{l}\text { Faculty members in this stage concentrate on the effect and influence of educational technology on student } \\
\text { outcomes, performance, abilities and the needed change for improvements. }\end{array}$ \\
\hline 5 Collaboration \\
\hline $\begin{array}{l}\text { Faculty members found in this stage are mainly concentrating on arranging and cooperating with other } \\
\text { faculty members concerning the use of educational technology. }\end{array}$ \\
\hline 6 Refocusing \\
\hline $\begin{array}{l}\text { Faculty members found in this stage are mainly concerned with finding new routes and practices to have } \\
\text { more benefits from the use of educational technology, with the chance of conducting major changes to the } \\
\text { use of educational technology or substituting it with other alternatives. }\end{array}$ \\
\hline
\end{tabular}

The use of CBAM's SoC involves the use of a questionnaire that includes 35 questions, and the questionnaire has been tested with different innovations and tools for reliability, internal consistency and validity [20]. While CBAM SoC provides well-defined measures and scorings, it also has limitations [16]:

- CBAM's SoC should be used for recognition purposes and not for observation or critique

- CBAM's SoC questions are not to be altered, tailored or changed

- CBAM's SoC outputs and analysis are to be validated with respondents

- CBAM's SoC must presume opinion and feedbacks

\section{$5 \quad$ Research Methodology}

The adopted methodology for this study is based on CBAM's SoC questionnaire, which is quantitative in nature [16]. The quantitative methodology is employed to inspect the current stages of concern among faculty members in Saudi universities towards use and engagement with m-learning. This research study required direct contributions from faculty members in order to outline and analyze numerical data and draw conclusions and results. The sample size was based on faculty members' 
contributions to this research from any Saudi university. The list of Saudi universities was obtained from the Saudi Ministry of Higher Education, and the results showed a total of 41 public and private universities [21]. The human resources department (or equivalent) was contacted at each university and the importance and significance of this study was explained, with a link to CBAM's SoC questionnaire attached. The questionnaire was built using Google Forms and was formatted according to Likert scale. Responses were received from 238 faculty members from 23 different universities. The data was grouped and analyzed using SPSS-v20. The next section presents the results of each stage in CBAM's SoC questionnaire.

\section{CBAM's Stages SoC Results}

The following table presents the results collected and analyzed from participants answering 35 questions distributed into 7 stages. The mean, standard deviation (SD) and percentage for each question and stage are presented in the table.

Table 2. Faculty members' stages of concern results

\begin{tabular}{|c|c|c|c|}
\hline Stage 0 - Awareness & Mean & SD & $\%$ \\
\hline I am more concerned about another educational technology & 1.3 & 0.619 & $26 \%$ \\
\hline I am not concerned about m-learning at this time & 1.6 & 0.653 & $32 \%$ \\
\hline I am busy with other tasks that are not related to m-learning & 2.7 & 1.194 & $54 \%$ \\
\hline I spend little time wondering about the use of m-learning & 2.8 & 0.461 & $56 \%$ \\
\hline In the meantime, other tasks are shifting my concern away from m-learning & 3.3 & 0.639 & $66 \%$ \\
\hline Group - s0 & 2.34 & 0.713 & $47 \%$ \\
\hline Stage 1 - Informational & Mean & $S D$ & $\%$ \\
\hline I have very limited knowledge about m-learning & 2.4 & 0.604 & $48 \%$ \\
\hline I would like to discuss the possibility of using m-learning & 3.3 & 0.728 & $66 \%$ \\
\hline $\begin{array}{l}\text { I would like to know what resources are available if we decide to adopt m- } \\
\text { learning }\end{array}$ & 4.2 & 0.844 & $80 \%$ \\
\hline $\begin{array}{l}\text { I would like to know what the use of m-learning will require in the immediate } \\
\text { future }\end{array}$ & 4.7 & 0.655 & $94 \%$ \\
\hline I would like to know how m-learning is better than what we have now & 4.7 & 0.472 & $94 \%$ \\
\hline Group - s1 & 3.82 & 0.621 & $76 \%$ \\
\hline Stage 2 - Personal & Mean & $S D$ & $\%$ \\
\hline I am concerned about the consequences of m-learning on my professional status & 3.2 & 0.627 & $64 \%$ \\
\hline I am concerned about the decision makers in the new m-learning system & 3.4 & 1.126 & $68 \%$ \\
\hline I am concerned about the needed change in my teaching or administration & 4.2 & 1.799 & $84 \%$ \\
\hline $\begin{array}{l}\text { I am concerned about having information related to required commandments } \\
\text { when using m-learning }\end{array}$ & 3.4 & 0.532 & $68 \%$ \\
\hline I am concerned to know if my role will need change when I use m-learning & 3.7 & 1.081 & $74 \%$ \\
\hline Group - s2 & 3.58 & 1.033 & $72 \%$ \\
\hline Stage 3 - Management & Mean & $S D$ & $\%$ \\
\hline $\begin{array}{l}\text { My concerns are related to not being able to organize myself on a daily basis for } \\
\text { the use of m-learning }\end{array}$ & 4.3 & 1.669 & $86 \%$ \\
\hline $\begin{array}{l}\text { My concerns are related to the possibility of having conflict between my } \\
\text { interests in m-learning and my work responsibilities }\end{array}$ & 3.5 & 0.686 & $70 \%$ \\
\hline My concerns are related to failure to manage all that m-learning requires & 3.1 & 0.974 & $62 \%$ \\
\hline My concerns are related to time exhausted working with non-academic issues & 4.3 & 0.986 & $86 \%$ \\
\hline
\end{tabular}




\begin{tabular}{|c|c|c|c|}
\hline related to m-learning & & & \\
\hline My concerns are related to the time spent coordinating tasks and users & 3.8 & 1.530 & $76 \%$ \\
\hline Group - s3 & 3.8 & 1.169 & $76 \%$ \\
\hline Stage 4 - Consequence & Mean & $S D$ & $\%$ \\
\hline My concerns are related to students' thoughts about m-learning & 3 & 0.790 & $60 \%$ \\
\hline My concerns are related to the effect of m-learning on students & 2.8 & 0.397 & $56 \%$ \\
\hline $\begin{array}{l}\text { My concerns are related to assessing my impact on my students' performance } \\
\text { and understanding }\end{array}$ & 3.2 & 1.333 & $64 \%$ \\
\hline $\begin{array}{l}\text { My concerns are related to being able to motivate my students to have more } \\
\text { effective engagement with m-learning }\end{array}$ & 2.9 & 0.476 & $58 \%$ \\
\hline $\begin{array}{l}\text { My concerns are focused on being able to attain student feedback in order to } \\
\text { change m-learning activities and practices }\end{array}$ & 2.2 & 0.685 & $44 \%$ \\
\hline Group - s4 & 2.82 & 0.736 & $56 \%$ \\
\hline Stage 5 - Collaboration & Mean & $S D$ & $\%$ \\
\hline My concerns are related to assisting my colleagues in their use of m-learning & 1.2 & 0.324 & $24 \%$ \\
\hline $\begin{array}{l}\text { My concerns are related to building relationships with colleagues in our faculty } \\
\text { and outside faculty on the use of m-learning }\end{array}$ & 1 & 0.247 & $20 \%$ \\
\hline $\begin{array}{l}\text { My concerns are related to publicizing the practice of m-learning with other } \\
\text { departments and colleagues }\end{array}$ & 1.1 & 0.156 & $22 \%$ \\
\hline $\begin{array}{l}\text { My concerns are related to organizing my tasks and activities with others to } \\
\text { maximize the m-learning effect }\end{array}$ & 1 & 0.277 & $20 \%$ \\
\hline My concerns are related to what other colleagues are doing in this area & 1.8 & 0.474 & $36 \%$ \\
\hline Group - s5 & 1.22 & 0.295 & $24 \%$ \\
\hline Stage 6 - Refocusing & Mean & $S D$ & $\%$ \\
\hline $\begin{array}{l}\text { I am at a confident level of using m-learning, it can provide better learning that } \\
\text { the traditional approach }\end{array}$ & 1.1 & 0.502 & $22 \%$ \\
\hline I find myself concerned about adjusting my use of m-learning & 1.4 & 0.635 & $28 \%$ \\
\hline I am concerned about improving m-learning instructional approach & 1 & 0.660 & $20 \%$ \\
\hline $\begin{array}{l}\text { I am concerned about changing the use of m-learning according to the } \\
\text { experiences of students }\end{array}$ & 2.1 & 0.251 & $42 \%$ \\
\hline I am concerned about how to supplement and enrich the m-learning experience & 1.5 & 0.719 & $30 \%$ \\
\hline Group - s6 & 1.42 & 0.554 & $28 \%$ \\
\hline
\end{tabular}

\section{$7 \quad$ Results and Discussion}

This section presents and discusses the results with respect to each stage in CBAM's SOC framework. Moreover, general discussion on the results and categories are presented for all stages.

\subsection{Awareness-stage (0)}

The mean average for this stage is (2.34), which indicates that the majority of faculty members are not classified in this stage according to CBAM's SoC methodology. In this stage the highest mean of (3.3) was for faculty members announcing that other tasks are shifting their concern from using m-learning. The second highest mean of (2.8) was related to the fact that many faculty members spend little time wondering about the use and engagement with m-learning. The third highest mean of (2.7) was related to the fact that faculty members are busy with different tasks that are not related to m-learning. The last two questions in this 
section had the lowest mean of (1.6) for faculty members not concerned about mlearning at this time, which shows that the majority of faculty members have concerns. Moreover, the mean of (1.3) shows that faculty members are not concerned about another educational technology.

\subsection{Informational-stage (1)}

The mean average for this stage was (3.82), which shows that a larger number of participants do agree with suggestions and concerns for this stage. The highest mean for this stage was (4.7), and two questions in this stage had that value: one related to how m-learning is better than the current practices, and the other pertaining to the immediate future needs of implementing m-learning. Moreover, the question related to the available resources in case of adopting m-learning had the mean of (4.2), which signals major interest in having more resources that can be distributed and used through m-learning technologies. A mean of (3.3) was related to the question of discussing the possibility of using m-learning. The lowest mean of (2.4) in this stage was related to faculty members having limited knowledge about e-learning. The previous result shows that the majority of participants are found in the middle in the Likert scale, by not totally agreeing or disagreeing with what the questions proposed, thus it was concluded that faculty members are unaware of their current knowledge, as they are not able to measure it due to the absence of benchmarks in the use and engagement with m-learning.

\subsection{Personal-stage (2)}

The mean average for this stage was (3.58), which shows that the majority of faculty members are agreeing with what is proposed in this SoC. The highest mean in this stage was (4.2) for the question related to the needed change of faculty members in terms of teaching or administration. The result shows that most faculty members have that as a major concern in this stage. The second highest mean of (3.7) was related to the need to change instructors' role when adopting m-learning. The previous value shows that it is a high concern for this question with respect to the personal stage. The third highest mean of (3.4) was recorded for two questions in the personal stage, one related to having information related to required commandments of using m-learning, and the other to their concern about decision makers for the adopted m-learning system. The lowest mean in this category was (3.2), which was related to the consequences of m-learning on faculty members' professional status.

\subsection{Management-stage (3)}

The mean average for this stage was (3.8), which shows major agreement for what is proposed in this stage of concern. The highest mean in this stage was (4.3) and it was found in two questions. The first question was related to faculty members organizing themselves for using m-learning, and the second was related to needed time exhausted working with non-academic issues related to m-learning. The second 
highest mean of (3.8) was related to the concern about time spent coordinating tasks and users. The third highest mean of (3.5) was related to the possibility of having conflict between faculty members interested in m-learning and work responsibilities. The lowest mean in this stage was (3.1), related to faculty members' concern about failing to manage all that $\mathrm{m}$-learning requires.

\subsection{Consequence-stage (4)}

The mean average for this stage was (2.82), which shows moderate agreement on the concerns related to this stage. The highest mean in this stage was (3.2) related to the concern of assessing faculty members' impact on students' performance and understanding. The second highest mean of (3) was related to faculty members' reflection on students' thoughts about e-learning. The third highest mean of (2.9) was related to faculty members being able to motivate students to have more effective engagement with m-learning. The fourth highest mean of (2.8) was related to faculty members' concern for the effect of m-learning on students. The lowest mean in this stage was (2.2), related to faculty members' concern about being able to attain student feedback in order to modify and develop m-learning activities and practices.

\subsection{The collaboration-stage (5)}

The mean average for this stage was (1.22), which shows that majority of participants do not agree with what is proposed in this stage. The highest mean in this stage was (1.8) related to faculty members' concern about what other colleagues are doing in this area. The second highest mean of (1.2) was for the concern related to faculty members assessing other colleagues in their use of m-learning. The third highest mean (1.1) was for the question related to publicizing the practice of $\mathrm{m}$ learning with other departments and colleagues. The lowest mean of (1) was found for two questions, one related to the concern of faculty members building relationships with colleagues in their faculty and outside on the use of m-learning, and the other to the concern of organizing their tasks and activities with others to maximize the $\mathrm{m}$ learning effect.

\subsection{The refocusing-stage (6)}

The mean average for this stage was (1.42), which shows that the majority of participants are not found in this stage of concern. The highest mean in this stage was (2.1), related to faculty members' concern about changing the use of m-learning according to the experiences of students. The second highest mean of (1.5) was for the concern related to how faculty members supplement and enrich the m-learning experience. The third highest mean of (1.4) was for the concern related to faculty members' capability of adjusting the use of m-learning. The result shows that most participants do not agree with that concern. The fourth highest mean of (1.4) concerned faculty members' ability to adjust the use of m-learning. The lowest mean 
in this stage was (1), related to faculty members' concern for improving m-learning instructional approach.

\section{Discussing the Investigation Phase-General Results}

CBAM SoC results concerning the defined stages identified the main concerns of faculty members in relation to the use of m-learning in Saudi Arabia and provide indications of other stages that can be used as a benchmark for future comparison on any change in policy, technology and practices. Table (3) shows a summary of the average mean of each stage of concern obtained from faculty members concerning the use of m-learning in Saudi universities. The highest mean in all stages was (3.8), related to informational and management stages of concern. The previous stages are concerned with faculty members having information on how to operate and utilize the m-learning technology, and being able to manage tasks, resources and time with respect to their responsibilities and m-learning activities. In addition, CBAM's SoC provides three categorizations for the stages impact, task and self $[15,16]$. The results in Table (4) show that the highest mean is for the task category, and this category in CBAM's SoC indicates that most participants in this research study are concentrating on the task related to the use of m-learning, and they are defined in this category.

Table 3. Stages of concern sections results

\begin{tabular}{|l|c|c|c|}
\hline \multicolumn{1}{|c|}{ Group } & Mean & SD & \% \\
\hline Group - s0 & 2.34 & 0.713 & $47 \%$ \\
\hline Group - s1 & 3.82 & 0.621 & $76 \%$ \\
\hline Group -s2 & 3.58 & 1.033 & $72 \%$ \\
\hline Group - s3 & 3.8 & 1.169 & $76 \%$ \\
\hline Group - s4 & 2.82 & 0.736 & $56 \%$ \\
\hline Group - s5 & 1.22 & 0.295 & $24 \%$ \\
\hline Group - s6 & 1.42 & 0.554 & $28 \%$ \\
\hline
\end{tabular}

Table 4. Stages of concern categories results

\begin{tabular}{|l|c|c|c|c|}
\hline \multicolumn{1}{|c|}{ Categories } & Stages & Mean & SD & \% \\
\hline Impact & $4,5,6$ & 1.82 & 0.528 & $36 \%$ \\
\hline Task & 3 & 3.8 & 1.169 & $76 \%$ \\
\hline Self & $0,1,2$ & 3.24 & 0.789 & $65 \%$ \\
\hline
\end{tabular}

\section{Conclusion}

There are different assessment models used to evaluate faculty members' concern, use and interaction with educational technology. Choosing the right model can prove to be a difficult procedure with different concerns involved in deciding on the appropriate assessment tool. Many models discussed in this study were found to lack the necessary breadth and methodical approach to assess and substantiate results. On the other hand, the use of CBAM framework was found to provide a systematic 
approach using three different tools (SoC, $\mathrm{LoU}$ and IC) that assess the use of educational technology from three different aspects. This study used $\mathrm{SoC}$ to define the concern of faculty members in Saudi universities with m-learning. Participants comprised 238 faculty members and the results defined them according to CBAM's SoC methodology to be in the informational and management stage, which can be classified into two stages for SoC. Moreover, CBAM's SoC provides another classification of categorizing participants results as self, task and impact. The results show that participants in this study were categorized in the task category, which means that participants' concerns are related to operations, activities and management of tasks related to m-learning. Using those results gives an indication of the necessity for more consideration of training and drive for using m-learning in Saudi Arabia in order for participants to reach the higher results of impact category.

\section{References}

[1] Kounaves, S., Archer, L., King, H., \& Pegram, E. (2016). Science Learning and Engagement in the Digital Age: Understanding the Effect of Mobile Technology on Adult Engagement Experiences at a Natural History Museum. Mobile Learning FuturesSustaining Quality Research and Practice in Mobile Learning, 361.

[2] Badwelan, A., Drew, S., \&Bahaddad, A. A. (2016), "Towards Acceptance M-Learning Approach in Higher Education in Saudi Arabia”, International Journal of Business and Management, 11(8), 12. https://doi.org/10.5539/ijbm.v11n8p12

[3] Alhabeeb, A., Alhabeeb, A., Rowley, J., \& Rowley, J. (2017). Critical success factors for eLearning in Saudi Arabian universities. International Journal of Educational Management, 31(2), 131-147. https://doi.org/10.1108/IJEM-01-2016-0006

[4] Aldhaban, F. A. (2016). Exploratory Study of the Adoption and Use of the Smartphone Technology in Emerging Regions: Case of Saudi Arabia.

[5] Alharbi, O., H. Alotebi, A. Masmali, and N. Alreshidi. "Instructor Acceptance of Mobile Learning in Saudi Arabia: A Case Study of Hail University." International Journal of Business and Management 12, no. 5 (2017): 27. https://doi.org/10.5539/ijbm.v12n5p27

[6] Matar, N. (2017). Presenting Structured Evaluation Framework Towards E-Learning Adaption In Jordanian Universities-The Use Of Cbam-Soc Framework", Journal Of Theoretical And Applied Information Technology, 95(5), 1008.

[7] Min, M. (2017). Teachers who Initiate Changes with an Ebook-Integrated Curriculum: Revisiting the Developmental Assumptions of Stages of Concerns in the Concerns-Based Adoption Model. Alberta Journal of Educational Research, 63(1).

[8] Matar, N. (2017). Defining E-Learning Level of Use in Jordanian Universities Using CBAM Framework. International Journal of Emerging Technologies in Learning, 12(3). https://doi.org/10.3991/ijet.v12i03.6497

[9] Sandholtz, J. H. (1997). Teaching with technology: Creating student-centered classrooms. Teachers College Press, Teachers College, Columbia University, 1234 Amsterdam Ave., New York, NY 10027.

[10] Neff, K. J. (1998). Technology as a catalyst for reinventing an institution. New Directions for Community Colleges, 101, 5-13. https://doi.org/10.1002/cc.10101

[11] Gillespie, K. H. (Ed.). (1998). Using technology in faculty development: practicalexamples (Winter ed. Vol. 76): Jossey Bass. 
[12] Howland, J., \&Wedman, J. (2004). A Process Model for Faculty Development: Individualizing Technology Learning. Journal of Technology and Teacher Education, 12(2), 239-262.

[13] Lumpe, A., \& Chambers, E. (2001). Assessing teachers' context beliefs about technology use. Journal of Research on Technology in Education, 34, 93-107. https://doi.org/10.1080/15391523.2001.10782337

[14] Anderson, S. E. (1997). Understanding teacher change: Revisiting the concerns based adoption model. Curriculum Inquiry, 27(3), 331-367. https://doi.org/10.1111/0362$\underline{6784.00057}$

[15] Tunks, J., \& Weller, K. (2009). Changing practice, changing minds, from arithmetical to algebraic thinking: an application of the concerns-based adoption model (CBAM). Educational Studies in Mathematics, 72(2), 161. https://doi.org/10.1007/s10649009-9189-X

[16] George, A. A., Hall, G. E., Stiegelbauer, S. M., \& Litke, B. (2008). Stages of concern questionnaire. Austin, TX: Southwest Educational Development Laboratory.

[17] Roach, A. T., Kratochwill, T. R., \& Frank, J. L. (2009). School-based consultants as change facilitators: Adaptation of the concerns-based adoption model (CBAM) to support the implementation of research-based practices. Journal of Educational and Psychological Consultation, 19(4), 300-320. Chicago. https://doi.org/10.1080/10474410802463304

[18] Donovan, L., Green, T. D., \& Mason, C. (2014). Examining the 21st century classroom: Developing an innovation configuration map. Journal of Educational Computing Research, 50(2), 161-178. https://doi.org/10.2190/EC.50.2.a

[19] Hollingshead, B. (2009). The concerns-based adoption model: A framework for examining implementation of a character education program. NASSP bulletin, 93(3), 166-183. https://doi.org/10.1177/0192636509357932

[20] Shotsberger, P. G., \& Crawford, A. R. (1996). An Analysis of the Validity and Reliability of the Concerns Based Adoption Model for Teacher Concerns in Education Reform Chicago.

[21] Saudi Arabia Ministry of Higher Education (2017) [Accessed 30th of December, 2017, from https://www.moe.gov.sa/en/Pages/default.aspx]

\section{Author}

Mohammed Al Masarweh is an Assistant Professor of Software Engineering at College of Business in Rabigh, King Abdulaziz University, Saudi Arabia, since January 2017. He published many research papers in many different international journals. His main research interests include interface design, remote guidance system, visual recognition and attention and software engineering, M-learning, Elearning, management information systems.

Article submitted 2018-01-24. Resubmitted 2018-10-25. Final acceptance 2018-11-01. Final version published as submitted by the authors. 